\title{
Bring a Foreign Language and Its Cultures to Saudi EFL University-Level Classrooms
}

\author{
Ali Ayed S. Alshahrani ${ }^{1}$ \\ ${ }^{1}$ Department of English, College of Arts, University of Bisha, Bisha, Saudi Arabia \\ Department of English, College of Arts, University of Bisha, Bisha, Saudi Arabia. Tel: 966-17-623-8101. E-mail: \\ alalshhrani@ub.edu.sa
}

$\begin{array}{lc}\text { Received: April 10, } 2017 \quad \text { Accepted: April 23, } 2017 \quad \text { Online Published: July 15, } 2017 \\ \text { doi:10.5539/ijel.v7n4p83 } & \text { URL: http://doi.org/10.5539/ijel.v7n4p83 }\end{array}$

\begin{abstract}
This study aims to investigate the effects Twitter has as a social networking platform on the development of Saudi EFL psychological variables (attitude, confidence, motivation, interest in L2 culture, social interaction and engagement), actual learning outcomes and the relationship between these psychological variables and their results. Twitter provides a valued accessible window to the target culture and promotes cross-cultural competence and comprehension that is focused on meaning rather than form, as well as repeated exposure to L2 cultural products, practices, perspectives and the target language. A sample of 39 students enrolled in an English course during the second semester of the 2014-2015 academic year, as well as two non-native English speakers (NNSs) working at the English Program, agreed to participate in the study. It adopts a combined inductive-deductive research approach to fulfil the research purpose and answer the research questions. The findings of this study underscore the latent use of the Twitter microblogging platform in EFL classes, as well as revealing the positive impact upon Saudi EFL students' social interaction (engagement), enthusiasm and interest in learning more about L2 culture in English language classes.
\end{abstract}

Keywords: L2 culture, social interaction, confidence, Twitter, social networking

\section{Introduction}

Learning one or more foreign language in schools, institutes and universities is common worldwide. The underlying goal beneath that is to create accessible windows of communication between foreign language learners and the target language community members. Therefore, besides being proficient in the target community language (in terms of accuracy and fluency), learners must have an adequate level of knowledge concerning the target language culture (the board term) and what is the appropriate manner of language use (both verbally and non-verbally) to avoid misunderstandings or breaks in communication due to cultural aspects. The learners should be presented with as many cultural experiences of the target culture components as possible when acquiring the target language, as "the true content of the foreign language course is not the grammar and the vocabulary of the language, but the cultures expressed through societal interactions" (Seelye, 1993). Therefore, L2 learners cannot truly learn the language without acquiring knowledge about its culture and native speakers.

Culture is an umbrella term that covers all sides of human life. Young et al. (2011) presented a definition of cultures that complies with its four sides. Firstly, culture is viewed as the aesthetic sense that reveals the artistic image of a community in terms of arts, artifacts, cinema, literature and media. Secondly, culture is a social sense that embraces set morals, laws, customs, habits values and interpersonal relations shared by a population. Thirdly, it is perceived in a semantic sense which contains the conceptualization system that governs the thinking and perception processes. Finally, culture is observed as a sociolinguistic/pragmatic that encompasses background knowledge, language codes, social and paralinguistic skills. Thus, culture is not simply a body of knowledge but rather a social interactive framework in which people live and communicate shared meanings with each other. This study adopts the later definition.

This view of culture depicts language as a vital and fundamental component and the interrelatedness of language and culture in a way that one cannot describe the two without losing the significance of either (Brown, 2007). It also endorses the idea that a successful learning of a foreign language demands having an adequate level of cultural experiences (Byram, 2012; Norton \& Toohey, 2011), and that, inevitably, learning a language in isolation 
of its cultural roots prevents learners from being socialized into its contextual use (Cheng, 2013).

A closer look at the current learning situations of English as a foreign language in Saudi schools and universities reveals that culture is left out of the foreign language classroom and that focus is placed on grammatical rules and vocabulary. This is a narrow and outdated view of language as a code that consists of words and a series of rules that connect words together. If language is only viewed in this manner, language learning just involves learning vocabulary and the rules of constructing sentences. This understanding of language sees language as fixed and finite and does not explore the complexities involved in using it to communicate. Textbooks seldom include any information on values, attitudes and beliefs in L2 culture due to religious and cultural concerns, which consequently results in intercultural incompetence with EFL; as their knowledge, skills and abilities avert them from participating in activities where the target language is the primary communicative code (Hall \& Verplaetse, 2000). However, language which should be "open, dynamic, energetic, constantly evolving and personal" (Shohamy, 2007, p. 5), embodies the rich complexities of communication. This expanded view of language also makes educational experiences more engaging for students. Language is not a rigid content to be memorized but a way of seeing, understanding and interconnecting with the world and each language user uses his or her language(s) differently to do this. Learning a new language involves learning how to use words, rules (language as a code) and knowledge about the target culture and its appropriate social practices to communicate with speakers of the language (Svalberg, 2007). Hence, integrating culture within a language is a need that should be performed in a manner that complies with religious and cultural concerns, that tolerates EFL learners in interacting and socializing within the target language culture and does not involve additional costs to the institute.

\section{Background}

The rapid progress in social networking platforms such as Twitter increases the suitability level of these applications as a learning medium to be used when acquiring about the target language culture. Twitter, the learning platform in this study, promotes socially active and interactive engagement with authentic content between learners to create a rich and engaging learning environment for foreign language learners with an ease of access, as well as flexibility in time, venue and the format of learning. Technology helps to place most responsibility for negotiating meaning in the hands of the learners; this learner-centered approach allows students to start with what they know and build their own understanding of culture (Kukulska-Hulme, 2010).

The technology platform provides a valued accessible window to the target culture and promotes cross-cultural competence and comprehension focused on meaning rather than on form, as well as repeated exposure to L2 cultural products, practices and perspectives - and the target language itself (Bueno, 2009). Hence, successful integration of an electronic platform involves appropriate authentic digital content, together with inquiry learning into instruction, to create a rich and meaningful environment in which students interact with authentic data and build their own understanding of a foreign culture's products, practices and perspectives to promote students' cultural and intercultural understandings (Moore, 2006).

Social networking sites, such as Twitter, Instagram, Snapchat, Facebook and LinkedIn, allow users to connect, share and interact with each other, maintaining online relationships and leading to community building (Thorne 2010). SN represents genuine examples of Bax's (2011) Computer Assisted Language Learning (CALL) and Second Language Acquisition (SLA) normalization (fully integration). At this stage, language learning tasks and CALL applications will be fundamental components of a learner's daily real-world use of language that demand the functional linguistic and intercultural skills to seamlessly carry out communicative actions and interactions in the L2 (Chun, 2016). Despite SN's reputation for personal interaction, it has not been widely embraced in education. Although there are an increasing number of academic studies related to various social media tools, many are not empirically based, nor do they offer strong theoretical advances (Chen, 2013).

Reviewing the pertinent literature on using Twitter in a second and/or foreign language learning environment revealed a paucity of studies that make contributions to the development of EFL learners' linguistic competence and cultural understandings of the target language culture. Most studies had investigated the effect of using Twitter on the foreign language learners' attitudes (Antenos-Conforti, 2009; Gunuc et al., 2013; Lin, Hoffman, \& Borengasser, 2013; Lomicka \& Lord, 2012; Perez-Sabater \& Montero-Fleta, 2015), confidence (Fewell, 2014; Castrillo de Larreta-Azelain, 2013), motivation (Junco et al., 2013; Kim \& Lim, 2010; Leis, 2014; Lin et al., 2013; Luo \& Gao, 2012; Pollard, 2014), interest in L2 culture (Lomicka \& Lord, 2012), as well as social interaction and engagement (Kassens-Noor's, 2012; Lomicka \& Lord, 2012; Perifanou, 2009; Preston et al., 2015). Most studies were descriptive in nature; only two rigorous comparison-based studies by Lomicka \& Lord (2012) and Perifanou (2009) utilised an experimental design approach that compared the use of Twitter versus 
non-Twitter use, employing objective learning outcome measures to assess actual learning outcomes using objective measures (e.g., test scores) instead of using student self-reported perceptual data.

The findings of these studies serve as a starting point to investigate the impact of using Twitter as a microblogging platform in authentic English language learning classrooms on the confidence, motivation, perception, attitudes and academic achievements of Saudi EFL students. Moreover, they add to the dearth of research regarding how Twitter can contribute to developing EFL learners' proficiency in the Asian EFL context, as well as using it to develop L2 linguistic competence and widen their understanding of the target language culture.

Therefore, the aim of this study is to investigate the effects of Twitter as a social networking platform, on the development of Saudi EFL psychological variables (attitude, confidence, motivation, interest in the L2 culture and social interactions and engagements), actual learning outcomes and the relationship between these psychological variables and their actual results. Thus, the present study was conducted to elicit answers to the following three questions:

i) Does using Twitter in an English language course improve participants' perception toward English as a foreign language?

ii) Does using Twitter in the English course improve participants' academic achievement?

iii) Is there any significant relationship among these psychological variables and students' post-test scores?

\section{Methods}

\subsection{Research Design}

The study adopts a combined inductive-deductive research approach to fulfill the research purpose and to answer the research questions; this combination enables the researcher to: test the suitability of the existing theories for the participants of the study; to validate, modify or even reject the existing theories, or; to put forward new theories based on the collected data. Therefore, a multimodal methodology which values both empirical (quantitative) and hermeneutic (qualitative) inquiries is used. This integration of methods adds breadth, richness and depth to our understanding (Denzin \& Lincoln, 2005)

\subsubsection{Participants}

The study was carried out in a Saudi university with more than four hundred students enrolled in the English Language Bachelorette Program. A sample of thirty-nine students (39) registered in the vocabulary building course during the second semester of the 2014-2015 academic year agreed to participate in the study. The participants were then randomly assigned into conventional and experimental groups (see Table 2).

Table 1. Participants' distribution

\begin{tabular}{ll}
\hline Conventional Group & Experimental Group \\
\hline $\mathbf{2 0}$ & 19 \\
\hline
\end{tabular}

The participants' proficiency levels ranged from pre-intermediate to intermediate, as defined by the Common European Framework of Reference for the English Language. Prior to conducting the study, the participants were informed in writing that their identities would remain anonymous and their participation was voluntarily and would not affect their grades in the course should they decided not to complete the study. Personal information would be kept confidential and the collected data would only be used for the purposes of the research. Two non-native English speakers (NNSs) working in the English program also agreed to participate in the study; they were not teaching the participants during that semester.

\subsection{Data Collection Instruments}

This study adopted a mixed-method design to collect quantitative and qualitative data. A survey questionnaire and achievement pre-test/post-test instruments were selected. The survey collected data about the participants' attitudes towards learning English, their motivations, confidence interest in L2 culture and social interaction (engagements). The 15 five-level Likert scale items of this section derived from the Lomicka \& Lord (2012) questionnaire on social networking used in an educational context. The questionnaire items assess participants' perceptions and attitudes towards the English language, attitudes to L2 speakers and interest in L2 culture, as well as motivations to learn English and collaborative learning through engagement and social interaction with peers and instructors. Early drafts of the questionnaire were then reviewed against the specific aims of the study 
and the threat of a lack of comprehensiveness. Some items were modified or changed and new items were added. Two experienced English faculty members were solicited for feedback to ensure the clarity and appropriateness of the questionnaire statements to the targeted participants. Suggested changes were reviewed and the questionnaire was reedited to the final format prior to being piloted. The results indicated that the questionnaire had an internal consistency coefficient of 0.83 - higher than the 0.70 value Dörnyei (2003) considered as acceptable in conducting a questionnaire due to the complexity of the second language acquisition process nature.

The second tool used to collect data was the course prerequisite final exam serving as the pre-test, as well as the course final exam that served as the post-test. The results of these tests served as an indicator of the participants' gains of linguistic knowledge and cultural understanding through using the appropriate words or phrases in the appropriate social situation.

\subsection{Materials and Procedure}

The study was designed to endorse socially active interactions of the learners with peers and NSs via authentic examples of language use in a variety of situations (Fig. 1) presented through the Twitter platform in an accessible and flexible way, as well as independent of methodological approaches (Gonzalez, 2009).

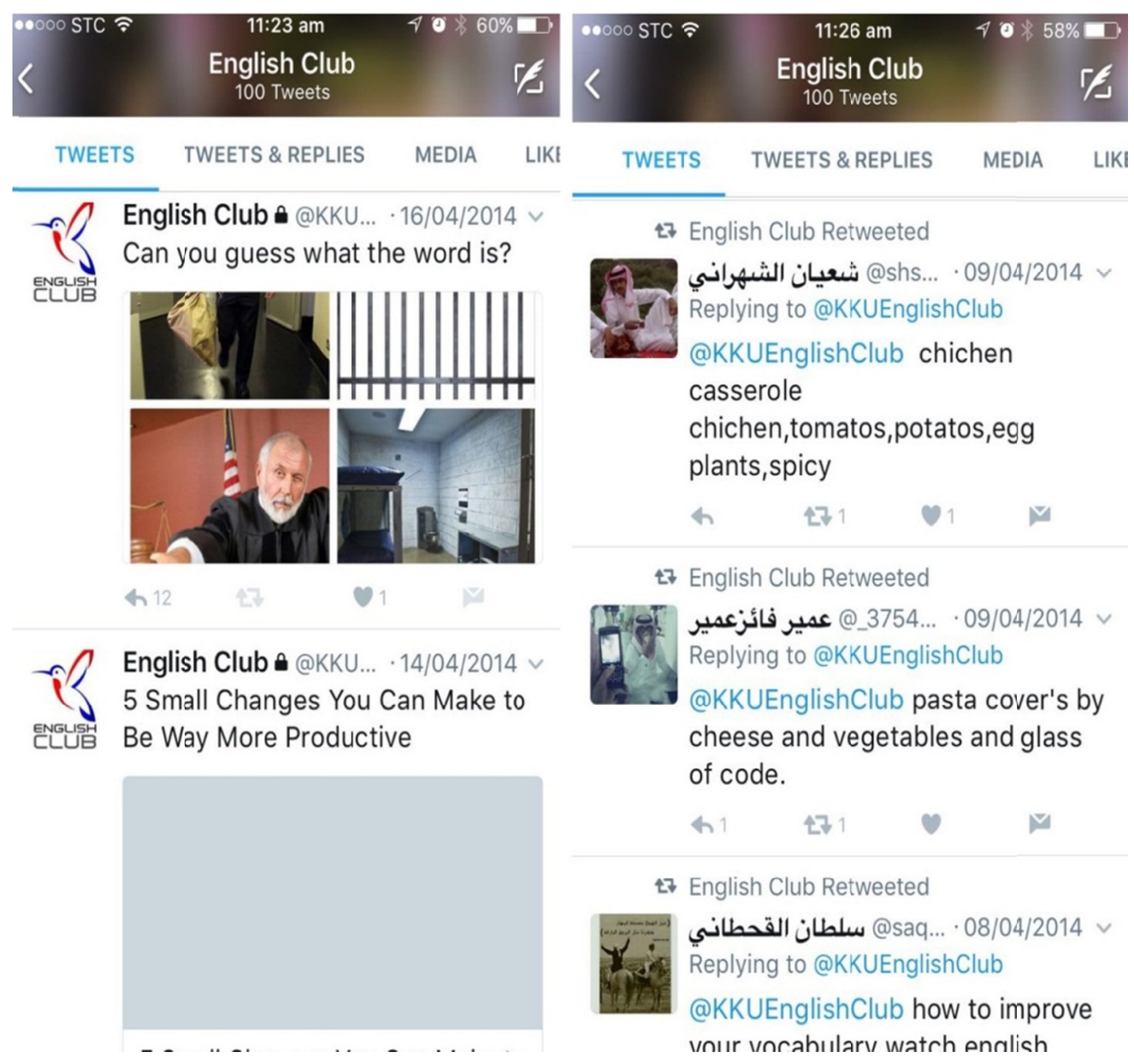

Figure 1. Caption of participants tweets

The study content was an integration of the Intensive English Language course with a digital media content and tasks, created to promote a rich, meaningful and engaging learning context for creating an authentic understanding of English as a foreign language and its culture. It also maximizes the opportunities for participants' exposure to a combination of authentic L2 daily life situations presented in arrays of video clips, links to audio files, images, newspapers headlines and articles, as well as dialogues to build their L2 linguistic competence and cultural knowledge (Stephens, 2011). 
To achieve the study purposes, participants were provided with basic Twitter information and technological training prior to class. A protect course account on Twitter was created and participants were informed to send their Twitter IDs to be added to the account (Fig. 2). The course instructor explained to the participants the nature of the weekly five tweets and their expected replies. A tweet was posted every day (Sunday to Wednesday) by the course instructor. The fifth tweet was sent after class on Thursday as an assessment of their understanding of the topic (summative assessment). Their answers are required (mandatory) and counted as a set of class marks. Participants are encouraged to post tweets related to the unit theme and interact with their peers and NNSs. Extra marks were added to the students' course marks at the end of the semester for tweets that demonstrated their thoughts concerning the topic or being built on what peers and NNSs have tweeted. In the last week of the semester, students' personal information was replaced by a unique number assigned to be used in the online survey and in the final examination of the course. Students' final exam marks were provided at the end of the academic year.
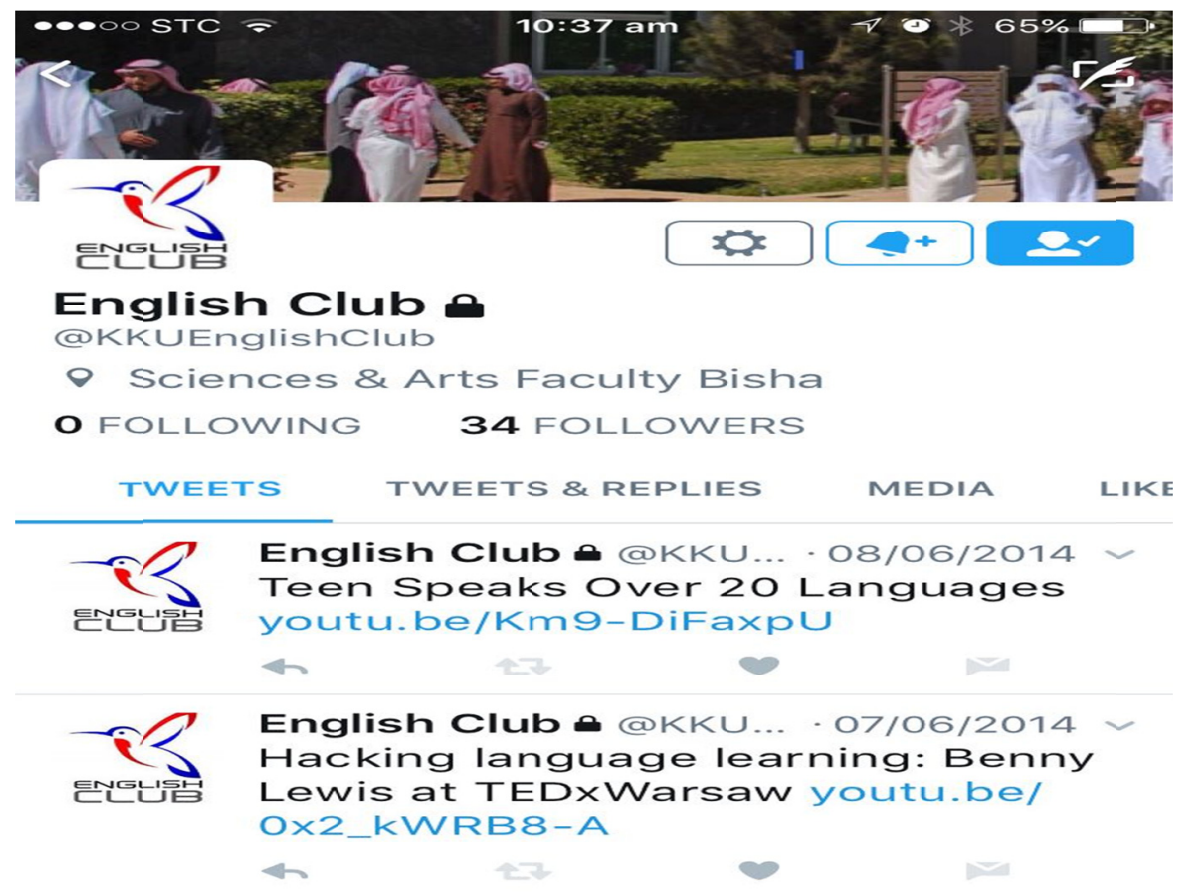

Figure 2. The course account on Twitter

\section{Results and Discussion}

SPSS software (Version 23) was used to code and analyze the collected data from the questionnaire. Cronbach's internal consistency reliability alpha was computed for each of the main study major subsections of the questionnaire (see Table 2). A high internal Cronbach's alpha was found for each subscale.

Table 2. Reliability analyses for the study $(\mathrm{N}=39)$

\begin{tabular}{llll}
\hline & N of items & Cronbach's Alpha & Cronbach Alpha \\
\hline Attitude & 3 & .823 & .76 \\
L2 culture & 3 & .860 & .79 \\
Social Interaction & 3 & .858 & .84 \\
Motivation & 3 & .857 & .85 \\
Confidence & 3 & .843 & .80 \\
\hline
\end{tabular}

Question One: Does using Twitter in an English Language Course improve participants' perception toward English as a foreign language?

The answer to participants' perception is presented in terms of their attitude towards English, confidence, 
motivation, interest in L2 culture and their social interaction (engagement). Participants' attitudes, motivation, confidence, interest in L2 culture and social interaction were calculated and the mean scores, percentages and frequencies were used to indicate the influence of using Twitter to introduce culture into their language classes.

EFL learners had positive perceptions towards the implementation of the social networking microblogging platform (Twitter) as a learning platform based on their answers to the Likert scale questionnaire submitted upon completion of the study. As shown in Fig.2, Twitter made the course more interesting (31/39 or 82\%), and 28/39 or $78 \%$ of the participants spent more time in this course in comparison with other English courses. They attribute that to the joy they found in doing the course Twitter assignments more than the traditional writing (29/39 or 79.5.1\%). These findings are in accordance with previous studies of Lin, Hoffman and Borengasser (2013), Lomicka \& Lord (2012), Antenos-Conforti, (2009) and Perez-Sabater \& Montero-Fleta (2015), but they contradict the Gunuc et al. (2013) study, where $67 \%$ of the participants found Twitter not interesting.

\section{L2 Attitude}

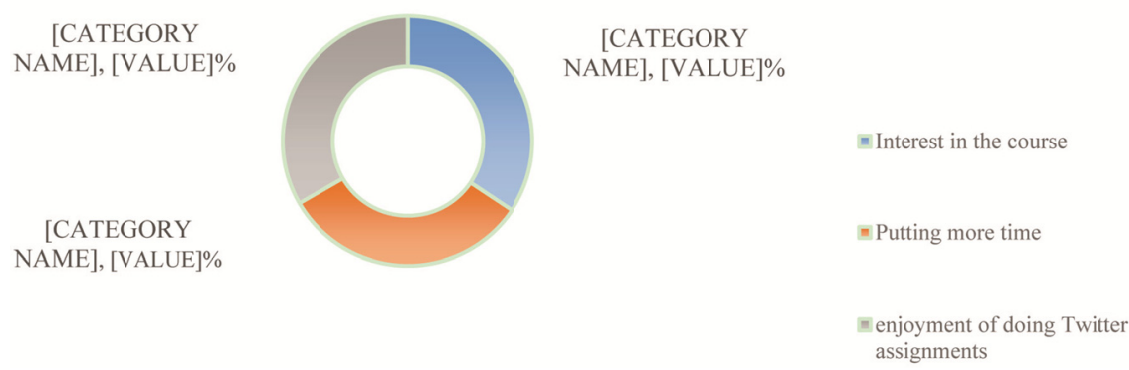

Figure 3. Experimental group participants' attitudes to L2 after using Twitter

Participants' confidence levels were high at the end of the study; these findings were in line with those Castrillo de Larreta-Azelain (2013) and Fewell (2014) studies. The participants in this study had a high level of confidence in their general abilities in using English as L2 learners $(74.5 \%$ or $25 / 39$ of the students, as represented in Fig. 3). Most participants (77.3\% or 27/39) indicated that Twitter helped in building their confidence in their writing abilities and $85.1 \%$ or $33 / 39$ in learning the language.

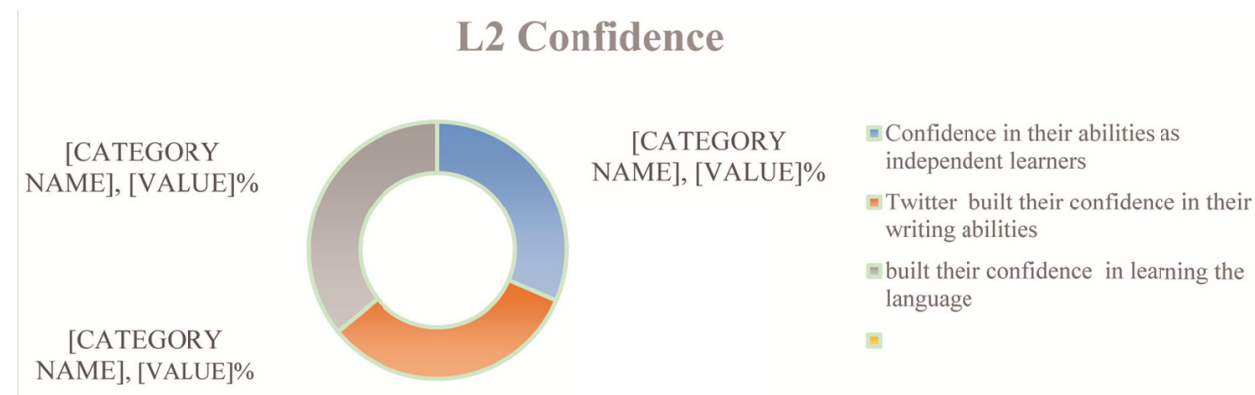

Figure 4. Experimental group participants' confidence in using L2

The participants revealed that using Twitter reduced their learning anxiety (Fig. 4). 31 students (79.7\%) denoted that Twitter increased their motivation in learning the language and that tweets and replies of the course instructors to their tweets enriched their learning opportunities, gave encouragement on the platform and increased student engagement; which predictably increased their motives to learn English (26/39 or $67.1 \%$ and $28 / 39$ or $73.7 \%$ respectively). These findings aligned with the findings in Junco et al. (2013), Leis (2014), Lin et al. (2013) and Luo \& Gao (2012) and Pollard (2014). 


\section{L2 Motivation}

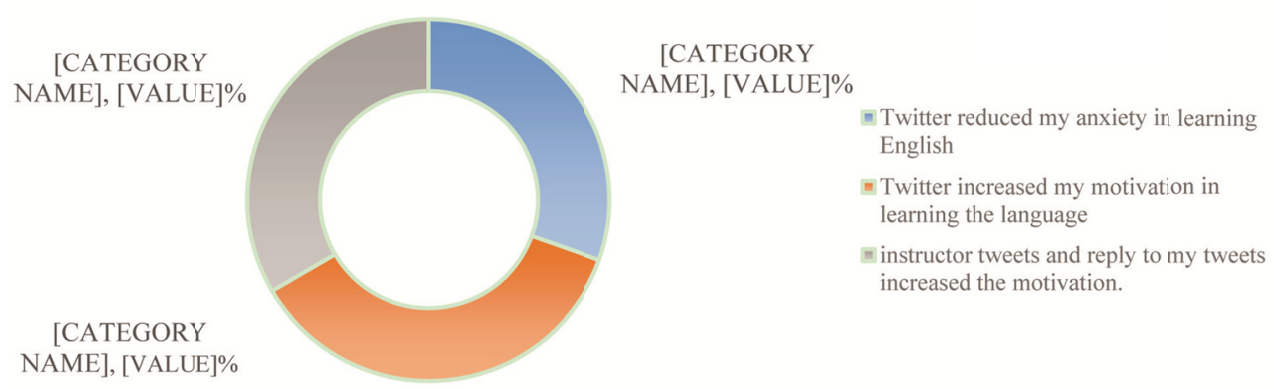

Figure 5. Experimental group participants' motivation towards L2 after using Twitter

Most participants (32/39) revealed that implementing Twitter in their class enhanced their knowledge of L2 use in actual daily situations and in understanding the English culture better than in their normal English classes (Fig. 5). The participants admitted the usefulness of using real-life vocabulary to use in an authentic forum for communication (tweets) about their daily routine and to read and reply to video clips or text segments from actual English language speaking communities (89.1\%). Participants' interest in L2 culture is also reported in Lomicka \& Lord's (2012) study of French, as L2 speakers revealed positive attitudes and enthusiasm involved in authentic communication with native French speakers outside the classroom, which enhanced their language levels as well their knowledge of French culture.

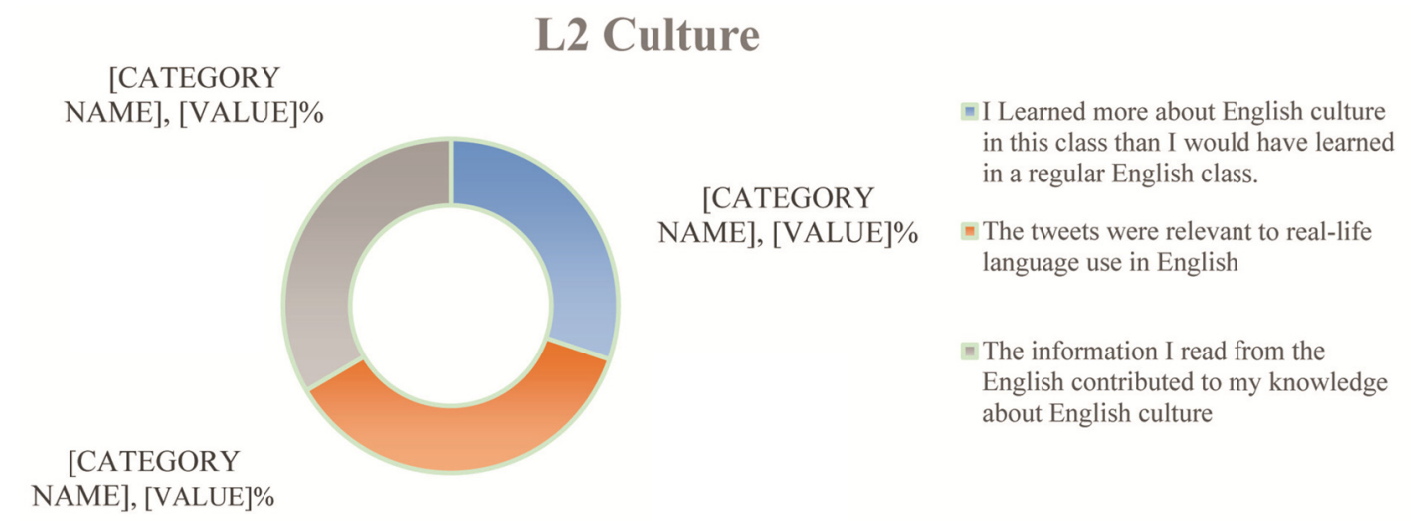

Figure 5. Experimental Group Participants' interest in L2 culture after using Twitter

The findings of the questionnaire reflected active engagement and a high level of participation among the participants. As represented in Fig. 6, they indicated that reading their peer responses to their tweets helped them in noticing the points that they had forgotten (33/39 or $84.48 \%$ ). They reported benefits in learning from interacting with each other related to the course work and assignments, as well as from each answer or responses to a tweet building upon the previous tweet by either adding additional information or presenting a different points of view (79.2\%). The findings also showed learners' willingness to interact with one another and wishing that their colleagues had tweeted more often $(82.1 \%)$. These findings echo the findings of previous studies conducted by Kassens-Noor's (2012), Lomicka \& Lord (2012) and Preston et al. (2015). 


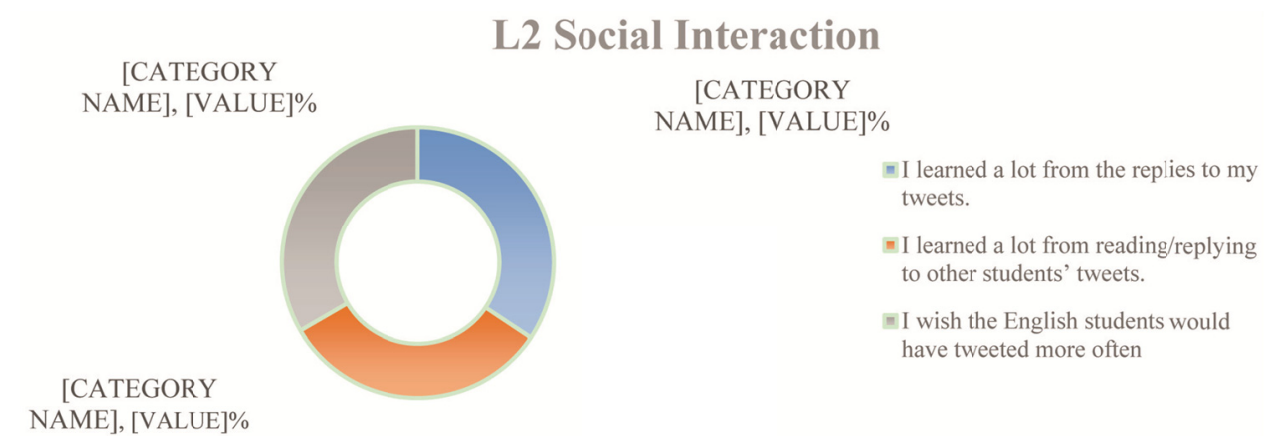

Figure 6. Experimental group participants' social interaction

Question Two: Does using Twitter in the English Course improve participants' academic achievement?

Normal distribution, means and standard deviations were calculated for the achievement tests (pre- and post-test) for both groups. The t-test for two independent samples was applied to detect significant change $(p<0.05)$ in the performance of the achievement test between the conventional and experimental groups.

The pre-test and post-test scores of all participants were statistically tested to confirm whether the data was normally distributed. The Shapiro-Wilk test was then applied, since the sizes of the samples were less than 50 per group ( $n=20$ for the conventional group and $n=19$ for the e-portfolio group) and, according to Ricci (2005), the Shapiro- Wilk test is the most powerful test for smaller sample sizes (under 50). The results presented in Table 3 indicate that the $\mathrm{p}$ value is greater than 0.05 and, therefore, the data is considered not to be normally distributed.

Table 3. Pre-test and post-test scores tests of normality

\begin{tabular}{lllllll}
\hline & \multicolumn{5}{l}{ Kolmogorov-Smirnov } & \multicolumn{3}{l}{ Shapiro-Wilk } \\
\cline { 2 - 7 } & Statistic & $\mathrm{df}$ & Sig. & Statistic & df & Sig. \\
Pre-test & .126 & 39 & .123 & .962 & 39 & .212 \\
Post-test & .065 & 39 & $.200^{*}$ & .974 & 39 & .495 \\
\hline
\end{tabular}

Note. Significant at the $5 \%$ level $(\mathrm{p}<0.05)$.

Using an alpha level of .05 , an independent-sample $t$ - test was conducted to evaluate whether the pre-test results differed significantly between the participants' in the two groups. An examination of the group means indicates that students in the conventional group $(M=68.85, S D=18.35)$ performed better than their counterparts' colleagues in the in the experimental group $(M=62.16, S D=10.4)$. There was no statistical difference between the two groups, $t(37)=1.391, p=.172$.

Table 4. T-test results of the Pre-test scores

\begin{tabular}{|c|c|c|c|c|c|c|c|}
\hline & & & & & \multicolumn{3}{|c|}{ t-test for Equality of Means } \\
\hline \multirow{3}{*}{ Pre-test } & Group & $\mathrm{N}$ & Mean & SD & Std. Error Mean & df & Sig. (2-tailed) \\
\hline & Experimental & 19 & 62.16 & 10.40 & 2.4 & \multirow{2}{*}{37} & \multirow{2}{*}{.172} \\
\hline & Conventional & 20 & 68.85 & 18.35 & 4.1 & & \\
\hline
\end{tabular}

Note. Significant at the $5 \%$ level $(\mathrm{p}<0.05)$.

The post-test data was analyzed by an independent samples t-test (Table $\mathrm{x}$ ) and the findings revealed no significant difference in the performance of the two groups in the achievement test $t(37)=.253, p=.801$. A slight difference was observed in the experimental group post-test score mean $(M=72.052, S D=12.2)$ compared to their counterparts in the in the conventional group $(M=71.05, S D=2.78)$. 
Table 5. T-test results of the post test scores

\begin{tabular}{lllllllll}
\hline & & & & \multicolumn{4}{c}{ t-test for Equality of Means } \\
\hline Post-test & Group & $\mathrm{N}$ & Mean & SD & Std. Error Mean & T & df & Sig. (2-tailed) \\
& Experimental & 19 & 72.052 & 12.2 & 2.80 & .253 & 37 & .801 \\
& Conventional & 20 & 71.050 & 12.5 & 2.78 & & \\
\hline
\end{tabular}

Note. Significant at the $5 \%$ level $(\mathrm{p}<0.05)$.

Despite a lack of statistical significant difference in the performance of the two groups in the post-test, a positive difference in the scores mean was noticed in both groups ( 9.9 for the experimental group and 2.2 for the conventional group), which indicates a better performance of the experimental group in the post-test (see Fig. $x$ ). This difference in the post-test results among the two groups was harmonized with the findings of Junco et al. (2013) and Kuh (2009) studies, where the experimental group results yielded higher averages than students who did not use the social networking tool.

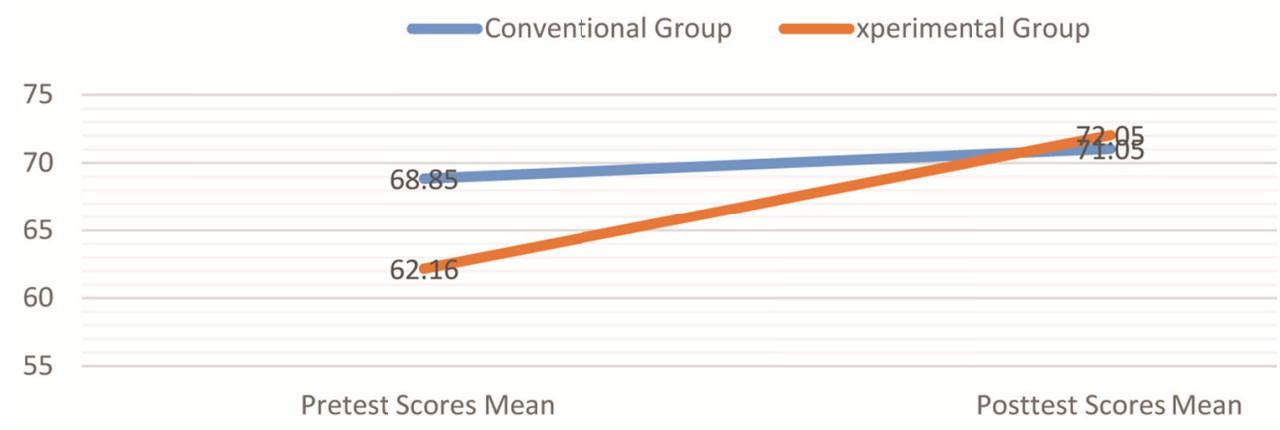

Figure 7. The mean scores of the conventional and experimental groups' pre and post tests

Question Three: Is there any significant relationship among these psychological factors and students' post-test scores?

\section{Relationship between Psychological Factors and the Post-test Test}

The Pearson product moment correlations were calculated to investigate the relationships between EFL learners' psychological factors and the post-test scores (alpha set $=.05$ ). The results represented in Table 6 indicates a correlation between two psychological factors and the post-test scores. There was a strong correlation in the EFL learners' interest in L2 culture and post-test score $(r=.56, p<.05)$, as well as a strong correlation with Learners'

Social Interaction $(r=.63, p<.01)$. These findings were in accordance with Van Vooren \& Bess's (2013) findings of a significant correlation between the use of Twitter and student performance, as well as with Evans's (2014) findings of a positive correlation existing between the usage of Twitter and students' engagement and social interaction with their tutors and classmates.

Table 6. Pearson's correlation results for psychological variances

\begin{tabular}{lll}
\hline & & Post-test Scores \\
\hline Confidence & Pearson Correlation & -.193 \\
Interest in L2 culture & Sig. (2-tailed) & .429 \\
& Pearson Correlation & $.564^{*}$ \\
Attitude to L2 language & Sig. (2-tailed) & .012 \\
& Pearson Correlation & .415 \\
Motivation & Sig. (2-tailed) & .077 \\
& Pearson Correlation & .249 \\
Social Interaction & Sig. (2-tailed) & .304 \\
& Pearson Correlation & $.627^{* *}$ \\
\end{tabular}

Note. ${ }^{*} \mathrm{p}<.05 . * * \mathrm{p}<.01$. 
A further investigation of these five psychological variables and their impact on the post-test scores was conducted. Stepwise regression tested these variables and decided which ones have the power to explain the variance going on with the post-test scores. All five psychological factors were entered as independent variables in a regression analysis. The Variance Inflation Factor (VIF) ranged from 1.4 to 1.8, and the Tolerance was between .3 and .7, which indicated that no multicollinearity exists in the regression model.

Table 7. Stepwise regression results for psychological variances predicting post test scores

\begin{tabular}{llllll}
\hline Stepwise & $\boldsymbol{R}$ & $\boldsymbol{R}^{2}$ & $\boldsymbol{\Delta} \boldsymbol{R}^{2}$ & F Change & $\begin{array}{l}\text { Sig. } \\
\text { Change }\end{array}$ \\
\hline Social Interaction & .564 & .319 & .278 & 7.947 & $.012^{*}$ \\
Interest in L2 culture & .697 & .486 & .421 & 5.200 & $.037^{*}$ \\
\hline
\end{tabular}

Note. $* \mathrm{p}<.05$.

The results of the stepwise regression analysis (see Table 7) indicated that $42.1 \%$ of the learners' post-test scores were explained by two variables: 1) The social interaction among the participants merely explained $27.8 \%$ of the variance in the learners' performance in the post-test, and; 2) Interest in L2 culture explained $14.3 \%$ of the variance in the post-test score. The other three variables (confidence, motivation and attitude) do not have any significant explanatory power for the variances in the post-test scores.

\section{Conclusions and Implication}

The findings of this study underscore the latent use of Twitter as a microblogging platform in EFL classes. They reveal its positive impact on Saudi EFL students' social interactions (engagement), enthusiasm and interest in learning more about L2 culture in English language classes. Twitter as a social networking medium has provided L2 learners with opportunities to practice their use of English outside their classes, by expressing and arguing their own ideas interactively.

The findings are consistent with previous studies that found using Twitter fostered positive learning and improvements to EFL participants' final exam results after implementing it as a learning platform in their classes (Junco et al., 2011; Junco et al., 2013; Kuh, 2009). EFL students' engagement and interaction with their peers and instructors, as well as their positive attitude towards English as an L2 and its culture, had empirically positive effects on the participants' test scores (Kassens-Noor's, 2012; Lomicka \& Lord, 2012; and Preston et al., 2015).

Despite the modest number of participants, the short period of conducting the study (one semester) and the possibility of a novelty effects, the findings of this study contribute to the growing literature of implementing social networking applications in Second Language Learning contexts in general. This study presented the real experience of EFL students' using their language knowledge and interaction with peers in a friendly atmosphere. The present study raised some questions for conducting longitudinal studies of at least two years; this would enable us to examine students' individual changes over time (i.e., personal learning experience, academic performance and psychological variables that change along with the use of Twitter).

\section{References}

Antenos-Conforti, E. (2009). Microblogging on Twitter: Social networking in intermediate Italian classes. In L. Lomicka \& G. Lord (Eds.), The Next Generation: Social Networking and Online Collaboration in Foreign Language Learning (pp. 59-90). San Marcos, TX: Computer Assisted Language Instruction Consortium.

Bax, S. (2011). Normalisation revisited: The effective use of technology in language education. International Journal of Computer-Assisted Language Learning and Teaching (IJCALLT), 1(2), 1-15. https://doi.org/10.4018/ijcallt.2011040101

Brown, H. (2007). Principles of language learning and teaching. New York, NY.

Bueno, K. (2009). Got film? Is it a readily accessible window to the target language and culture for your students? Foreign Language Annals, 42(2), 318-339. http://dx.doi.org/10.1111/j.1944-9720.2009.01023.x

Byram, M. (2012). Language awareness and (critical) cultural awareness-Relationships, comparisons and contrasts. Language Awareness, 21(1-2), 5-13. http://dx.doi.org/10.1080/09658416.2011.639887

Castrillo de Larreta-Azelain, D. (2013). Learners' attitude toward collaborative writing in e-language learning classes: A Twitter project for German as a foreign language. Revista Espanola de Linguistica Aplicada, 26, 
$127-138$.

Chen, H. (2013). Identity practices of multilingual writers in social networking spaces. Language Learning and Technology, 17(2), 143-170. Retrieved from http://ltt.msu.edu/issues/june2013/chen.pdf

Cheng, C. (2013). Reflections of College English Majors' Cultural Perceptions on Learning English in Taiwan. English Language Teaching, 6(1), 79-91. http://dx.doi.org/10.5539/elt.v6n1p79

Chun, D. (2016). The role of technology in SLA research. Language Learning \& Technology, 20(2), 98-115. Retrieved from http://ltt.msu.edu/issues/june2016/chun.pdf

Denzin, N., \& Lincoln, Y. S. (2005). The SAGE Handbook of Qualitative Research. London: Sage Publications Ltd.

Dornyei, Z. (2003). Questionnaires in Second Language Research: construction, administration, and processing. Mahwah, NJ: Lawrence Erlbaum Associates.

Evans, C. (2014). Twitter for teaching: Can social media be used to enhance the process of learning? Twitter for teaching. British Journal of Educational Technology, 45(5), 902-915. http://dx.doi.org/10.1111/bjet.12099

Fewell, N. (2014). Social networking and language learning with Twitter. Research Papers in Language Teaching and Learning, 5, 223-234.

Gunuc, S., Misirli, O., \& Odabasi, H. (2013). Primary school Children's communication experiences with Twitter: A case study from Turkey. Cyber psychology, Behavior, and Social Networking, 16(6), 448-453. http://doi.org/10.1089/cyber.2012.0343.

Hall, J. K., \& Verplaetse, L. S. (2000). The development of second and foreign language. Journal of Computer Assisted Language Learning and Teaching, 1(2), 1-15. http://dx.doi.org/10.1002/ets2.12124

Junco, R., Elavsky, C., \& Heiberger, G. (2013). Putting Twitter to the test: Assessing outcomes for student collaboration, engagement and success: Twitter collaboration \& engagement. British Journal of Educational Technology, 44(2), 273-287. http://doi.org/10.1111/j.1467-8535.2012.01284.x.

Junco, R., Heiberger, G., \& Loken, E. (2011). The effect of Twitter on college student engagement and grades: Twitter and student engagement. Journal of Computer Assisted Learning, 27(2), 119-132. http://doi.org/10.1111/j.1365-2729.2010.00387.x.

Kassens-Noor, E. (2012). Twitter as a teaching practice to enhance active and informal learning in higher education: The case of sustainable tweets. Active Learning in Higher Education, 13(1), 9-21. http://dx.doi.org/10.1177\%2F1469787411429190

Kim, S., \& Lim, K. (2010) A case study on the effects of microblogging as a learning activity to enhance ESL students' cultural knowledge and motivation to write in English. Multimedia-assisted Language Learning, 13(3), 155-174.

Kuh, G. (2009). The national survey of student engagement: Conceptual and empirical foundations. New Directions for Institutional Research, 141, 5-20. http://dx.doi.org/10.1002/ir.283

Kukulska-Hulme, A. (2010). Learning Cultures on the Move: Where are we heading? Educational Technology \& Society, 13(4), 4-14.

Leis, A. (2014). Encouraging autonomy through the use of a social networking system. The JALT Call Journal, $10(1), 69-80$.

Lin, M., Hoffman, E., \& Borengasser, C. (2013). Is social media too social for class? A case study of Twitter use. Tech Trends, 57(2), 39-45. https://doi.org/10.1007/s11528-013-0644-2

Lomicka, L., \& Lord, G. (2012). A tale of tweets: Analyzing microblogging among language learners. System, 40(1), 48-63. http://doi.org/10.1016/j.system.2011.11.001

Luo, T., \& Gao, F. (2012). Enhancing classroom learning experience by providing structures to microblogging-based activities. Journal of Information Technology Education: Innovations in Practice, 11(1), 199-211.

Norton, B., \& Toohey, K. (2011). Identity, language learning, and social change. Language Teaching, 44(4), 412-446. http://dx.doi.org/10.1017/S0261444811000309

Pérez-Sabater, C., \& Montero-Fleta, B. (2015) ESP vocabulary and social networking: The case of Twitter. Ibérica, 29, 129-154. 
Perifanou, M. A. (2009). Language micro-gaming: fun and informal microblogging activities for language learning. Communications in Computer and Information Science, 49, 1-14. https://doi.org/10.1007/978-3-642-04757-2_1

Pollard, E. A. (2014). Tweeting on the backchannel of a Jumbo-sized lecture Hall: Maximizing collective learning in a world history survey. The History Teacher, 47(3), 329-354. Retrieved from http://www.societyforhistoryeducation.org/pdfs/M14_Pollard.pdf

Preston, J., Jakubiec, B., Jones, J., \& Earl, R. (2015). Twitter in a bachelor of education Course: Student experiences. Learning Landscapes, 8(2), 301-319. Retrieved from http://www.learninglandscapes.ca/images/documents/l-no16/1l-no16-final-lr.pdf\#page.6

Ricci, V. (2005). Fitting distributions with R. Retrieved from http://cran.r-project.org/doc/contrib/Ricci-distributions-en.pdf

Seelye, H. (1993). Teaching culture: Strategies for intercultural communication (3rd ed.). Lincolnwood, IL: National Textbook Company.

Shohamy, E. (2007). Language Policy: Hidden Agendas and New Approaches. London: Routledge.

Svalberg, A. (2007). Language awareness and language learning. Language Teaching, 40(4), 287-308. https://doi.org/10.1017/S0261444807004491

Thorne, S. (2010). The intercultural turn and language learning in the crucible of new media. In F. Helm \& S. Guth (Eds.), Telecollaboration 2.0 for Language and Intercultural Learning (pp. 139-164). Bern: Peter Lang.

Van Vooren, C., \& Bess, C. (2013). Teacher tweets improve achievement for eighth grade science students. Journal of Education, Informatics \& Cybernetics, 11(1). Retrieved from http://www.iiisci.org/journal/CV\%24/sci/pdfs/HHB348DV.pdf

Young, T., \& Sachdev, I. (2011). Intercultural communicative competence: exploring English language teachers' beliefs and practices. Language Awareness, 20(2), 81-98. http://dx.doi.org/10.1080/09658416.2010.540328

\section{Copyrights}

Copyright for this article is retained by the author(s), with first publication rights granted to the journal.

This is an open-access article distributed under the terms and conditions of the Creative Commons Attribution license (http://creativecommons.org/licenses/by/4.0/). 